Christa Liedtke, Johannes Buhl, Najine Ameli

\title{
Designing value through less by integrating sustainability strategies into lifestyles
}

Originally published as:

Christa Liedtke, Johannes Buhl, Najine Ameli (2013):

Designing value through less by integrating sustainability strategies into lifestyles In: International Journal Sustainable Design, 2 (2), 167-180 
Christa Liedtke $^{a}$, Johannes Buhl ${ }^{a}$, Najine Ameli ${ }^{a}$

\section{Designing value through less by} integrating sustainability strategies into lifestyles

a Wuppertal Institut für Klima, Umwelt Ernergie $\mathrm{GmbH}$, Wuppertal, Germany

* Corresponding author: Christa Liedke, Wuppertal Institut, Döppersberg 19 , 42103 Wuppertal, Germany

E-mail: christa.liedtke@wupperinst.org

Phone: +49 202 2492-116

Fax: +49 202 2492-138 


\title{
Designing value through less \\ by integrating sustainability strategies into lifestyles
}

Christa Liedtke, Johannes Buhl, Najine Ameli

Wuppertal Institute for Climate, Environment and Energy,

Research Group 'Sustainable Production and Consumption',

Doeppersberg 19, Wuppertal 42013, Germany

E-Mail: christa.liedtke@wupperinst.org,johannes.buhl@wupperinst.org, najine.ameli@wupperinst.org

\begin{abstract}
The article argues for a need to overcome a conventional notion of product design. In this regard, the article offers an integrative and systemic approach to sustainable design.

Instead of focussing on objects, a user-centred perspective is adopted. A sustainable design of products and services requires the integration of production-orientated (efficiency and consistency) and consumption-orientated (sufficiency) strategies. The article introduces the concept of an indicator that is capable of comprehending a lifecycle-wide analysis of products and that favours the integration of existing sustainability strategies. The goal is not to design sustainable products but rather to design systems that manage to foster sustainable lifestyles. The article illustrates the usability of the introduced concept by showing examples of strategic integrative thinking in sustainable design from the Sustainable Summer Schools ${ }^{1}$.
\end{abstract}

Keywords: sustainable design strategies, lifecycle design, user-centred design, new design methods, Factor 10, MIPS

Biographical notes: Christa Liedtke is Director of the research group 'Sustainable Production and Consumption' at the Wuppertal Institute for Climate, Environment and Energy in Germany. She is also Visiting Professor for Sustainable Research in Design/Industrial Design at the Folkwang University of the Arts in Essen, Germany.

Johannes Buhl is Research Fellow in the research group 'Sustainable Production and Consumption' at the Wuppertal Institute for Climate, Environment and Energy.

Najine Ameli is Research Fellow in the research group 'Sustainable Production and Consumption' at the Wuppertal Institute for Climate, Environment and Energy.

\footnotetext{
${ }^{1}$ The Sustainable Summer Schools are organised every year by the Wuppertal Institute for Climate, Energy and Environment, University of Wuppertal, Folkwang University Essen, Aalto University Helsinki, University of Luzern and the UNEP Collaborating Centre on Sustainable Consumption and Production (for further information see sustainable-summer-school.org).
} 


\section{Introduction - design for sustainability}

In principle, the notion of design is broad. It has the potential to integrate aesthetic and functional as well as environmental, safety, cost and intangible considerations into products, services and systems (EU Commission 2009). It has to move beyond its conventional notion of pure product design (Walker 2008). Designers are no longer responsible only for the aesthetic form of new products, but rather must search for new solutions for sustainable product and service systems. Basically, the research in product service systems highlights their contribution towards a dematerialisation within the production and consumption system while offering benefits for producers and consumers alike regarding flexibility or economies of scale, leading to reduced marginal costs and thus to increased eco-efficiency (Halen et al. 2005). Manzini and Vezzoli (2002) already stressed a new mode of interaction between supply and demand requiring systemic thinking among, producers, retailers, suppliers and consumers throughout the lifecycle of goods. Eventually, when reconsidering design socially, it is about serving human needs by fostering social interaction. Instantly, the requirements for sustainable design become more complex, in terms of social embeddedness as well as in terms of grasping and anticipating the (environmental) impact of design. As Thackara (2005:1) stated by introducing his idea of "Design Mindfulness": If it was possible to "design our way into difficulty, we can design our way out".

Therefore, the question arises as to if there is always a need for new things. "The human demands are astoundingly constant: love, security, friendship, self-fulfilment and success. It is only the conditions that change constantly, and that is where the designers come in" (Rams 2011). The context and corresponding subjects must be addressed, rather than focussing on objects. Sustainable design needs to reflect its concepts systemically by focussing on the consumers and their social practices, because, so far, engaging in social interaction requires an appropriate consumption of goods and services (Warde 2005). Eventually, the design of socio-technical innovations triggers and promotes transition processes (Green/Vergragt 2002, Rootmans/Loorbach 2010). Since more than $80 \%$ of a product's environmental impact is determined at the design stage (EU Commission 2010), design plays a key role and is a formative element for sustainability transition and innovation processes.

The problem and further tasks arise out of this holistic understanding of design. Research on sustainable design lacks fundamental orientation within discrete methods from a transdisciplinary approach. This paper strives to develop a consistent and easy-to-grasp methodology to which designers can refer. We add to the preliminary work on Eco-Design, 
which was fundamentally influenced by lifecycle-wide thinking and closed loops, pushed in the early 1990s by Walter Stahel (1991) or Schmidt-Bleek (1993), and are thinking beyond the now most popular notion of cradle-to-cradle by Braungart and McDonough (2002). To put it in a nutshell: It is necessary to handle environmental services with caution or ecointelligently. Making more out of less becomes the prerogative in sustainable design.

In this respect, the important thing is not to coordinate the common three spheres of sustainability (economic, social, environmental), but to foster individual quality of life or personal meaning (Walker 2011) within social and environmental surroundings. Well-being should not be determined by the consumption of goods, but should rather become a programme for consuming less (Vezzoli 2006).

\section{Factor 10 and MIPS - concept and methodology}

Consequently, the question emerges, how much is 'less' and how do we achieve 'less'? Offering answers requires that we be able to observe and measure 'less'. The task of environmental scientists is then to offer an easy-to-grasp and easy-to-apply methodology that may guide designs concerning their environmental impact. Therefore, we elaborate a proper methodology to frame sustainable design. Examples of integrative service designs show how our introduced pressure indicator may be applied conceptually.

\section{Factor 10}

Nowadays, striving for economic growth reinforces existing production and consumption patterns in a resource-intensive way that already exceeds its planetary boundaries (Rockström et al. 2009). Expanding value chains, intensive infrastructural investments and even shorter product lifecycles simultaneously accelerate global resource consumption. Consequently, it has become extremely important to reduce global resource consumption equitably; meaning growth in resource extraction needs to be absorbed by industrial countries disproportionally, by a factor of 10 (Bringezu \& Bleischwitz 2009: 61). Factor 10 as a holistic concept is the result of efforts to define individual environmental space by giving an absolute cap from which a maximum consumption of resources can be derived.

Factor 10 attempts to make absolute and relative decouplings in resource consumption of economies (national, in regions, cities, companies or households) visible along value chains, via the analysis of their material intensities (MAIA) (Schmidt-Bleek 1993). Shifts in material intensity can be recognised, as can the relocation of hidden material footprints between stages 
in value chain processing. Material flows are far from becoming necessarily decoupled from production and consumption. Most recent models claim a reduction potential of $8 \%$ while fulfilling the planned economic growth path until 2030 in industrialised European countries such as Germany, France and Italy (Mayer et al. 2012). At the same time, the annual consumption of resources per capita accounts for up to 70-90 tons in Germany and the USA (including the production of exports, infrastructures, public demand and stocks). Factor 10 claims 6-8 tons of natural resources per capita being sustainable (Bringezu/Bleischwitz 2009, Schmidt-Bleek 2009, Lettenmeier 2012).

The results highlight the importance of holistic and strategically encompassing concepts to reach a reduction potential in industrialised countries by a factor of $10 \%$ or $90 \%$ in the same temporary dimensions. In this respect, Factor 10 is not, as Walker (2008: 5) argues, a strategy to reduce external effects by a product design within existing systems, but a concept that fundamentally challenges the production and consumption system as a whole. Sustainable design in terms of Factor 10 seeks not to (re-)design products more efficiently, but rather seeks to establish a production and consumption system that questions its functions (Karlsson/Luttrop 2006).

Consequently, it claims a fundamental cultural paradigm shift. Wishes need to be revisited by questioning the function and service rather than the form of products. It is crucial that the system of mass production and consumption should transform into a system based on sufficient scale. Production processes and business cases, forestry and soil, as well as work habits and lifestyles, housing, eating, mobility and leisure time, have to be revised. But how can sustainability of products and services be evaluated during the design process while thinking about the integration of sustainability strategies such as efficiency, consistency and sufficiency?

\section{Material Flow Analysis}

First, we need to introduce in more detail the rationale behind material intensity analysis indicated by material footprints on the micro-level for products or the total material requirement (in $\mathrm{kg}$ ) within material flows of whole economies (Ritthoff et al. 2002, SchmidtBleek 2009, Bringezu \& Bleischwitz 2009). First and foremost, it is crucial to understand that every human material use is associated to natural material flows in eco-systems. Continuously growing material turn-over of soil or timber has fundamental impacts on the life-sustaining functions and services of the ecosphere. The basic idea is that every input sooner or later becomes an output. Reducing the inputs reduces the overall burden much more effectively 
than specific output-orientated remedies. To date, we have looked for solutions that are at the end of the pipe. Usually, solutions are attributed to specified impacts such as the recycling of waste and the filtering of emissions from smokestacks or exhaust pipes. For instance, catalytic converters are supposed to diminish and filter harmful substances from combustion engines, eventually reducing emissions from traffic. It does not indicate the resources used or the impact coming from unused resource extraction while mining. Altogether, about $90 \%$ of the material lifted from nature does not appear in final goods. This means that the material footprint of every kilogram of industrial goods uses on average a bit more than $10 \mathrm{~kg}$ of natural resources. Material footprints denote the environmental burden from resource use that solutions at the end of pipe account for only inadequately (Lettenmeier et al. 2009).

The input-orientated approach has vast advantages since anthropogenic environmental intervention may be accounted for and displayed both fundamentally and comprehensively. The problem is that material flows are indications of turn-over. Consequently, some shortcuts occur. First, information about the quality of the resources summarised according to their rough categories (see below) is neglected in favour of quantity and clarity. The quantities do not differentiate between scarce (and hence expensive), affluent or toxic resources. One kilogram of e.g. coal, which is available relatively plentifully, equals one kilogram of e.g. indium (rare earth). Uni-dimensional indicators are always insufficient to cover eco-systemic complexities, whether they address resources or emissions. Qualitative indications (e.g. toxicity) need to be considered separately, when these are at stake.

In the end, when it comes to the application of the methodology for sustainable design, its easy-to-follow rationale of material flows is attractive to stakeholders who are not familiar with ecological complexities and is able to guide actions in the right direction. Material intensities are a more sound and reliable indicator of the environmental burden than outputorientated measures (Schmidt-Bleek 2009).

\section{Material Input per Service Unit (MIPS)}

The accounting methodology is described by material inputs per service unit (MIPS). It is closely related to the idea of material flow analysis (MFA) described above. Its indicators such as total material requirement (TMR) can be simply thought of as an aggregation of MIPS. In any case, a first step requires the collection of material intensities, which are all direct and indirect material inputs. MIPS allows for the measurement and evaluation of the ecological impact of a goods item on the micro-level (e.g. washing machine), delivering a certain service or value (clean clothes, in each case) (see Ritthoff et al. 2002, Mancini 2012). 
In other words: MIPS downscales the Factor 10 concept into a metric and tangible unit for goods. The material input is given in kilograms or tons. The service unit has no given dimension, but has to be defined in accordance to the specified service, for transport in $\mathrm{km}$ (per person) for example. The following categories are counted separately in that respect: biotic (or renewable) raw materials like timber, abiotic (or non-renewable) materials like coal, water, air and earth movement or erosion in agriculture and forestry. All raw materials that are necessary for production, use and disposal or recycling can be aggregated to the material footprint of goods (product or service), which is equivalent to the material input "from cradle to cradle" (Schmidt-Bleek 1993: 108). By simply setting the service unit as the denominator in relation to the whole material input, we calculate the item's material intensity or MIPS ${ }^{2}$.

\section{Insert Figure 1 about here}

Accordingly, the material input diminishes as the number of services grows. Simultaneously, the environmental damage diminishes with growing service performance (see Figure 1). This is why instead of disposing of products, re-using (e.g. second hand clothes), cascading or recycling (e.g. PET bottles become functional wear) are features of Factor 10 as a holistic concept. In this context, it is important to state that re-using only makes sense, for instance, if the material requirements of recycling are less than the material footprint of the primary product. Otherwise the demand for natural resources would be higher for recycling than for the production (see dashed lines in Figure 1).

\section{Integration of sustainable strategies and MIPS}

The examples mentioned above give a first glimpse into the integrative perspective of Factor 10 and MIPS. Sustainable design is not necessarily restricted to innovative product design in technological terms. The notion of a service unit offers perspectives for resource productivity apart from technological innovation. Social innovations are equally important when it comes to the realisation of ambitious reduction goals. The goal is a sufficient, i.e. absolute, decoupling of economic growth and resource consumption. Therefore, the systemic, lifecyclewide perspective integrates production and consumption as one system (Charter \& Tischner 2001, Wimmer et al. 2004). Sustainability strategies such as efficiency, consistency and

\footnotetext{
${ }^{2}$ Basically, MIPS is formulated formally as the following: MIPS $=$ MI/S, referring to MI as material intensity of a specifically defined service unit $\mathrm{S}$.
} 
sufficiency are discussed separately; efforts to integrate mainstream strategies are to date unknown. The MIPS methodology is able to approach the assessment of sustainability strategies in an integrative manner. The nominator or material input addresses efficiency and consistency, whereas the denominator or service unit addresses sufficiency. The following paragraph shows how to interpret MIPS in an integrative manner according to mainstream sustainability strategies in order to make abstract strategies assessable.

\section{Efficiency}

Narrowing sustainable strategies to all-in-one solutions is hardly feasible. Efficiency is not only a matter of technical progress, but also of social progress. As we pointed out earlier, it is fundamentally crucial that lifestyles become sustainable, since otherwise a resource-efficient production could be negated by rebound effects. Econometrics show that efficiency gains are directly negated up to $50 \%$ on average (Sorrel et al. 2009). That makes sustainable design more complex at first glance since it is about socio-technical solutions. At the same time, new opportunities open up for approaching efficiency. For instance, sharing services and products is highly efficient (e.g. car-sharing systems). Four commuters sharing one car instead of driving to work separately is more efficient by factor four, without an additional input of resources. Efficient resource management becomes efficient usage management (Liedtke et al. 2012).

\section{Consistency}

Instead of better, i.e. more efficient, production, consistency strategies seek to close ecological loops by designing products with materials that are completely recyclable or degradable, i.e. producing differently. Consequently, harmful emissions and disposals are minimised by the quality of materials. Intensity is not of interest in this respect. MIPS considers the principle of consistency via the notion of economy from cradle to cradle or circular flow economy. In MIPS, only primarily extracted resources are allocated and accounted for. Secondary materials, i.e. materials that are already in the closed-loop economy are not counted as further input and double-counting are avoided. Eventually, when we consider the products' material footprint, i.e. the unused material flows accompanying production, one third of material flows are not embodied in products at all, and are therefore not transferred into a loop economy. Hence, only $3 \%$ of material flows are recycled (Schmidt-Bleek 2009: 13). The majority is disposed of during the process of resource extraction or embodied in the infrastructures of transport and communications systems. It is 
challenging to pass them into a loop economy as no one has yet thought about how to dispose of them. This relocates the disposal issue respectively into developing countries (leakage effects). Economies are only truly consistent when hidden material flows - the material footprints - are considered. When considering specific small-scale solutions, a consistent product design is attractive. As soon as economy-wide material flows are taken into account, consistency becomes less attractive.

Nevertheless, efficiency and consistency are important strategies, which need to be taken into account. Some technical aspects of sustainable design in the concept of MIPS are shown in Figure 2.

\section{Insert Figure 2 about here}

\section{Sufficiency}

The most fundamental opportunities for integrative sustainable design lie in the denominator of MIPS, the service unit $\mathrm{S}$ (Schmidt-Bleek 2001). $\mathrm{S}=0$ is optimal, most efficient, since no resource-based service is demanded. $\mathrm{S}=0$ is an answer to the functional question of sustainable design, saying there is no additional marginal service supporting a gain in quality of life. Respectively, when $\mathrm{MI}=0$, the additional service is supplied immaterially. Take a walk, talk face-to-face are simple specifications of strategies that take sharing, slowing down and localising seriously. In this sense, a sufficient supply of services may lead to a gain of quality in life without losing the service.

Rethinking design this way leads to a functional design process that deal with necessities and additional utilities in qualitative terms. Is there a gain in quality of life? Are the costs (monetary and social) of maintaining the product too high? Are the social costs (i.e. time) too high to gain any marginal value? Sufficiency is not a strategy to meet existing consumption patterns, but to ask the question of why and how needs can be met while minimising environmental damage without losses in quality of life. As Beuys has pointed out: The righteous law of a qualitative production says, needlessness, absolute needlessness, is the goal aspired to, because without needlessness world problems will not be solved (Beuys et al. 1989: 48f).

Design has to face the challenge of providing immaterial goods by substituting resourceintensive innovations with social innovations that stem from resource-intensive hardware and infrastructure requirements (e.g. rare earth elements) as well as accelerated consumption patterns. A reduction in demand from sufficient lifestyles will introduce marginal consumers 
that are able to pay lower prices. A sustainable design needs to be capable of dealing with sufficiency by stopping sufficiency from being a victim of costs and benefits in terms of purchasing power, but by making sufficiency a characteristic of sustainable lifestyles - of costs and benefits in social terms.

\section{Examples for the design of sustainable arrangements}

Lifestyles combining hedonism and ascetics, aesthetics and form, emotionality and status, cultural homogeneity and heterogeneity, need to be addressed by adequate design. In this sense, product design has to be replaced by the design of social arrangements and by the production and the exchange of functions and services rather than material goods. Sustainable product design can be regarded as service systems that follow ideas like "value through less", "systems and swarms" (Liedtke et al. 2010), "designing utility" (Charter \& Tischner 2001), "hot-spot analysis" (Liedtke et al. 2010) and the didactic notion of transformational product design (see Laschke \& Hassenzahl 2011). The challenge is to embed sustainable concepts in rapidly changing consumption patterns and lifestyles. The baseline for assessing the environmental impact of design follows the introduced MIPS methodology and its implications ${ }^{3}$. At its core, (re-)design is processed by identifying the goods item's value chain, next by assessing its status quo (in terms of MIPS) and eventually optimising the design by either choosing different material inputs or by shifting focus onto the improvement of the service unit.

The concepts presented are adapted from the Sustainable Summer Schools. The summer school is an innovative campus consisting of workshops in which students, teachers, companies, and system experts develop sustainable and resource-efficient product service systems in an interdisciplinary and, if possible, trans-disciplinary fashion (Liedtke \& Ameli 2010, Liedtke et al. 2013).

\section{Phlox}

In "Phlox" for instance, developed by Prof. Brigitte Wolf, Marcel Befort, Christina Mertens, Carina Matzky, Jasmin Acar, Andrea Augsten, and Daniel Hyngar in 2010, people sharing housing may participate reciprocally by sharing services (e.g. Wi-fi), exploiting their diverse skills, experiences, talents and time budgets to meet needs, save resources and enhance

\footnotetext{
${ }^{3}$ For detailed scripts on how to apply the MIPS methodology and respective examples in product service design, we refer readers to Ritthoff et al. (2002) or Lettenmeier et al. (2009).
} 
quality of life by engaging in a social network (see Figure 3). Expanding the local coordination online, whole housing quarters can coordinate their services. Resources are governed by the community and localised as commons.

\section{Insert Figure 3 about here}

\section{FoodPrint}

Another concept following our scientific approach is FoodPrint (developed by Prof. Nina Gellersen, Luzius Schnellmann, Jenny Dobslaff, Kaya Erdal and Christian Wiciok in 2011), where the menu of a take-away restaurant is designed to reduce resource consumption, without dictating to customers how to manage their diets. The sovereignty of consumers is respected, but incentives are given for behavioural change. Customers are able to see the material footprint of their meals, to change the composition or ingredients of their meals while monitoring their material consumption. Ordering a soup with meatballs uses $13 \mathrm{~kg}$ of resources, while a soup with vegetables only needs three $\mathrm{kg}$ of resources, equalling a material footprint which is 'ecologically cheaper' by a factor of four (see Figure 4). Diets and habits can be recorded on individual customer cards that give incentives to change diet habits stepby-step by making behaviour transparent and comprehensible. Eating is embedded in a transformational service design, and social routines can be steadily innovated.

\section{Insert Figure 4 about here}

\section{Evaluation according to MIPS}

The introductory examples may be hypothetically evaluated according to MIPS. We do not strive to give absolute numbers indicating the environmental relief of the concepts, but give hints as to how to understand product service systems technically in order to evaluate them properly. Taking the first example of Phlox, which is basically about sharing, the interactive management of products and resources, Bootsman and Rogers (2011) refer to a collaborative lifestyle as part of collaborative consumption that is more a "socioeconomic groundswell" than a niche trend. Technically speaking, sharing is associated to MIPS in such a way that the service unit is provided by reducing its nominator (the material input), while the service is held constant (or even increases). Depending on the number of users, the input is governed in a logarithmically efficient manner. 
A recent evaluating study from Germany shows that forms of collaborative consumption such as systems of sharing or swapping do not necessarily lead to environmental relief. Rebound effects occur when money is saved and spent in other areas of consumption. Over all, the resource-efficiency potential for sharing systems (from customer to customer or C2C) is assessed as low to medium (Leismann et al. 2012). Tukker (2004) comes to the same conclusion, attributing to sharing systems a reducing potential of less than $50 \%$ compared to the reference situation. For instance, if the money saved from sharing Wi-fi-access is spent in full, whether sharing is ecologically beneficial depends on the material intensity of the substituting good. Sharing inherits potential for efficiency gains, but this does not determine whether there are sufficient accompanying behaviour patterns.

The second concept introduced, FoodPrint, implements incentives for sufficient behaviour. It addresses the service unit of MIPS. By asking which ingredients a meal is supposed to be composed of, FoodPrint is aiming at the number of calories (i.e. technically, our service unit) your meal includes. Leaving out the meatballs in the soup degrades chili con carne to chili sin carne. FoodPrint offers the choice of changing your service unit without dictating the correct amount of service units. In the short run, indirect rebound effects are likely. But due to the fact that the resource intensity (in terms of material footprint per monetary unit spent) of meat is relatively high, it is likely that money saved is spent in less resource-intensive areas of consumption limiting the rebound effects to low levels (EEA 2010: 86). In the long run, theoretically, sufficient behaviour puts a cap on resource consumption due to its diminishing returns in utility.

As a concluding remark, it has to be said that design becomes part of a creative, userintegrating approach to social routines and behavioural patterns. Products and services are part of lifestyles, and design has to consider them systemically rather than in isolation. It is not products that are sustainable, but lifestyles. Products and services embody natural resources from cradle to cradle, and designers need to take into consideration longevity or modularity of products, as well as sound potential for social innovation in product service systems.

\section{Conclusions}

Western lifestyles in Germany and the USA, for instance, account for 70 to 90 tons of resource use. A sustainable lifestyle in terms of a sustainable material footprint accounts for 6 
to 8 tons per capita, as the holistic rationale of Factor 10 suggests. Such a desirable drop in consumption will lead to considerable changes and impacts on individual and social lifestyles. The material footprint may guide design to shift from product-centred approaches to a systemic and user-centred approach in favour of socio-technical innovations that make 'less' possible. We have introduced the methodology of material intensities per service unit (MIPS), which allows one to observe and measure 'less' while offering an integrative approach in order to downscale mainstream sustainability strategies to the level of product service design. Due to rebound effects, technical (and to some extent social) innovations, as engineered, do not inevitably save resources and energy. Strategies focussing solely on efficiency of products cannot be successful unless they are accompanied by strategies that enhance social innovations that foster a paradigm shift in consumption patterns.

Sustainable design following MIPS may act thoughtfully in the well-known cognitive gap between environmental awareness and environmental behaviour. Therefore, design needs to address individual behaviour in social contexts within its environmental space according to Factor 10 . The trans-disciplinary integration of sustainability strategies within the concept of Factor 10 and the methodology of MIPS may help designers to do so.

Firstly, integrative and systemic design integrates sustainable strategies such as efficiency, sufficiency and consistency. When deciding to (re-)design a service, an integrative approach needs to consider material inputs from cradle to cradle, or consistently, with primary inputs having the greatest effect on resource management. Moreover, the goals of mitigating climate change and resource scarcity will not be met without considering the service unit from a fundamental, a sufficient, point of view. Does the unit enhance quality of life; is it meeting or generating needs?

In order to dematerialise sufficiently, design has to think systemically in a social way. Innovative design is not limited to the (re-)design of products by using new technologies or materials, but by embedding products in social contexts. The examples introduced hint at product service arrangements as a promising starting point for integrative thinking in design. Nevertheless, regarding our brief evaluation of 'less', the question arises as to how social innovations are able to replace material-based consumerism, since rebound effects stress the opposite. In this regard, further research is required that investigates product service systems empirically, requiring in turn a research design that engages users from the start (see Liedtke et al. 2012). 


\section{Literature}

Beuys, J., Fischer, K. \& Smerling, W. (1989). Joseph Beuys im Gespräch mit Knut Fischer und Walter Smerling. Köln: Kiepenheuer \& Witsch.

Botsman, R. \& Rogers, R. (2011). What's Mine is Yours: The Rise of Collaborative Consumption. How collaborative consumption is changing the way of life. UK: Harpercollins

Bringezu, S. \& Bleischwitz, R. (2009). Sustainable resource management: global trends, visions and policies. Sheffield, UK: Greenleaf.

Charter, M. \& Tischner, U. (2001). Sustainable solutions: developing products and services for the future. Sheffield, UK: Greenleaf.

EEA (2010). The European environment - state and outlook 2010: synthesis. Copenhagen: European Environment Agency.

EU Commission (2009). Design as a driver of user-centred innovation (Staff Working Document SEC(2009)501 final). Available at http://ec.europa.eu/enterprise/policies/innovation/policy/designcreativity/index en.htm (accessed on 1 August 2012).

Green, K. \& Vergragt, P. (2002). Towards sustainable households: a methodology for developing sustainable technological and social innovations, Futures 34(5), 381-400.

Halen, C. van, Vezzoli, C. \& Wimmer, R. (2005). Methodology for product service system innovation: how to develop clean, clever and competitive strategies in companies. Assen: Koninklijke Van Gorcum.

Karlsson, R. \& Luttropp, C. (2006). EcoDesign: what's happening? An overview of the subject area of EcoDesign and of the papers in this special issue. Journal of Cleaner Production, 14(15-16), 1291-1298.

Manzini, E. \& Vezzoli, C. (2002). Product-Service Systems and Sustainability. Opportunities for sustainable solutions. United Nations Environment Programme Division of Technology Industry and Economics Production and Consumption Branch. Paris, France. Available at: http://www.score-network.org/files//820_12.pdf (accessed on 13 February 2013).

Laschke, M. \& Hassenzahl, M. (2011). Things with attitude: Transformational Products. Create11 Conference, 1-2. Available at http://www.createconference.org/storage/create11 papersposters/Things with attitude.pdf (accessed on 1 August 2012).

Leismann, K. et al. (2012). Nutzen statt Besitzen: auf dem Weg zu einer ressourcenschonenden Konsumkultur: eine Kurzstudie. Berlin: Heinrich-Böll-Stiftung.

Lettenmeier et al. (2009). Resource productivity in 7 steps. How to develop eco-innovative products and services and improve their material footprint. Wuppertal Institute for Climate, Environment and Energy. Wuppertal Spezial 41. Available at 
http://wupperinst.org/uploads/tx_wupperinst/ws41.pdf (accessed 4 February 2013).

Lettenmeier et al. (2012). Scenarios for Sustainable Lifestyles 2050: From Global Champions to Local Loops (SPREAD). UNEP/Wuppertal Institute Collaborating Centre on Sustainable Consumption and Production (CSCP). Available at http://www.sustainablelifestyles.eu/fileadmin/images/content/D4.1_FourFutureScenarios.pdf (accessed on 1 August 2012).

Liedtke, C., Baedeker, C., Kolberg, S. \& Lettenmeier, M. (2010). Resource intensity in global food chains: the Hot Spot Analysis. British Food Journal, 112(10), 1138-1159.

Liedtke, C. \& Ameli, N. (2010). The concept of the sustainable summer schools. Documentation of the 2nd Sustainable Summer School, 14-19. Available at http://www.designwalks.org/fileadmin/designwalks/2nd_sss_booklet.pdf (accessed on 1 August 2012).

Liedtke, C., Welfens, M.J., Rohn, H. \& Nordmann, J. (2012). Living Lab: User-Driven Innovation for Sustainability. International Journal of Sustainability in Higher Education, 13(2), 106-118.

Liedtke, C., Buhl, J. \& Ameli, N. (2013). Microfoundations for sustainable growth with ecointelligent product service-arrangements. Sustainability 2013, to be published.

Mancini, L., Lettenmeier, M., Rohn, H. \& Liedtke, C. (2012). Application of the MIPS method for assessing the sustainability of production-consumption systems of food. Journal of Economic Behavior \& Organization, 81(3), 779-793.

McDonough, W. \& Braungart, M. (2002). Cradle to cradle: remaking the way we make things (1st ed.). New York: North Point Press.

Meyer, B., Meyer, M. and Distelkamp, M. (2012). Modelling green growth and resource effciency: new results. Mineral Economics, 24(2), 145-154.

Rams, D. (2011). Design for a more human environment. form 242. Available at http://www.form.de/w3.php?nodeId=6401\&lang=1\&pVId=954935540 (accessed on 1 August 2012).

Ritthoff, M.; Rohn, H. \& Liedtke, C. (2002). Calcualting MIPS : Resource productivity of products and services (No. 27e). Wuppertal Institute for Climate, Environment and Energy.

Rockström, J. et al. (2009). Planetary boundaries: exploring the safe operating space for humanity. Ecology and Society, 14(2), 32. Available at http://www. ecologyandsociety.org/vol14/iss2/art32/ (accessed on 29 November 2012).

Rotmans, J. \& Loorbach, D. (2010). Towards a better understanding of transitions and their governance. A systemic and reflexive approach. In Grin, J.; Rotmans, J. \& Schot, J. (Eds.). Transitions to sustainable development - new directions in the study of long term transformation change. New York: Routledge, 105-220. 
Schmidt-Bleek, F. (1993). The Fossil Makers. Translation of the book „Faktor 10 - das Maß für ökologisches Wirtschaften " by Robert Deumling, Berkeley. Available at http://www.factor10institute.org/files/the fossil_makers/FossilMakers_Intro.pdf (accessed 1 August 2012).

Schmidt-Bleek, F. (2001). MIPS and Ecological Rucksacks in Designing the Future. EcoDesign 2001: 2nd International Symposium on Environmentally Conscious Design and Inverse Manufacturing, Tokyo. Available at: http://www.factor10institute.org/files/design/EcoDesign_Tokyo_2001.pdf (accessed 1 August 2012).

Schmidt-Bleek, F. (2009). The Earth: natural resources and human intervention. London: Haus Pub.

Sorrell, S., Dimitriopolous, J. \& Sommerville, M. (2009). Empirical estimates of direct rebound effects: a review. Energy Policy, 37, 1356-1371.

Stahel, W. R. (1991). Langlebigkeit und Materialrecycling, Strategien zur Vermeidung von Abfällen im Bereich der Produkte. Essen: Vulkan Verlag.

Thackara, J. (2005). In the bubble: Designing in a complex world. Cambridge, Mass: MIT Press.

Tukker, A. (2004). Eight Types of Product-Service-Systems: Eight Ways to sustainability? Experiences From Suspronet. Business Strategy and the Environment, 13(4), 246-260.

Vezzoli, C. (2006). Design for sustainability: the new research frontiers.7th Brazilian Conference on Design.

Walker, S. (2008). Extant objects: designing things as they are. International Journal of Sustainable Design, 1(1), 4-12.

Walker, S. (2011). Form Beyond Function: practice-based research in objects, environment and meaning. International Journal of Sustainable Design, 1(4), 335-347.

Warde, A. (2005). Consumption and Theories of Practice. Journal of Consumer Culture, 5(2), 131-153.

Wimmer, W., Züst, R., Lee, K.-M. \& Alliance for Global Sustainability (2004). ECODESIGN Implementation : a systematic guidance on integrating environmental considerations into product development. Dordrecht: Springer. 
Figure 1: Analysis of two lifecycles in series

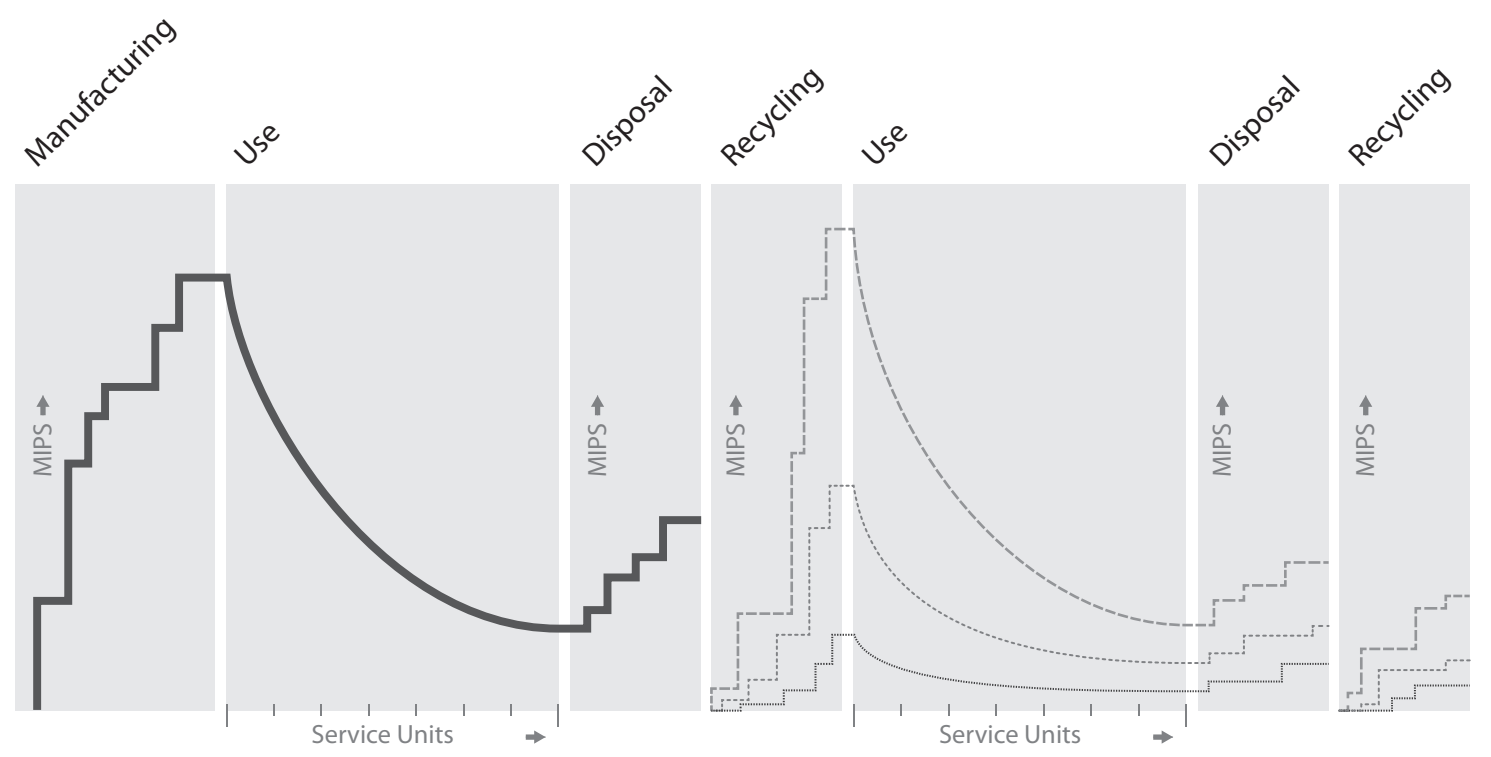

Source: Own depiction based on Schmidt-Bleek 1993, p. 112

Figure 2: Aspects concerning sustainability design in MIPS

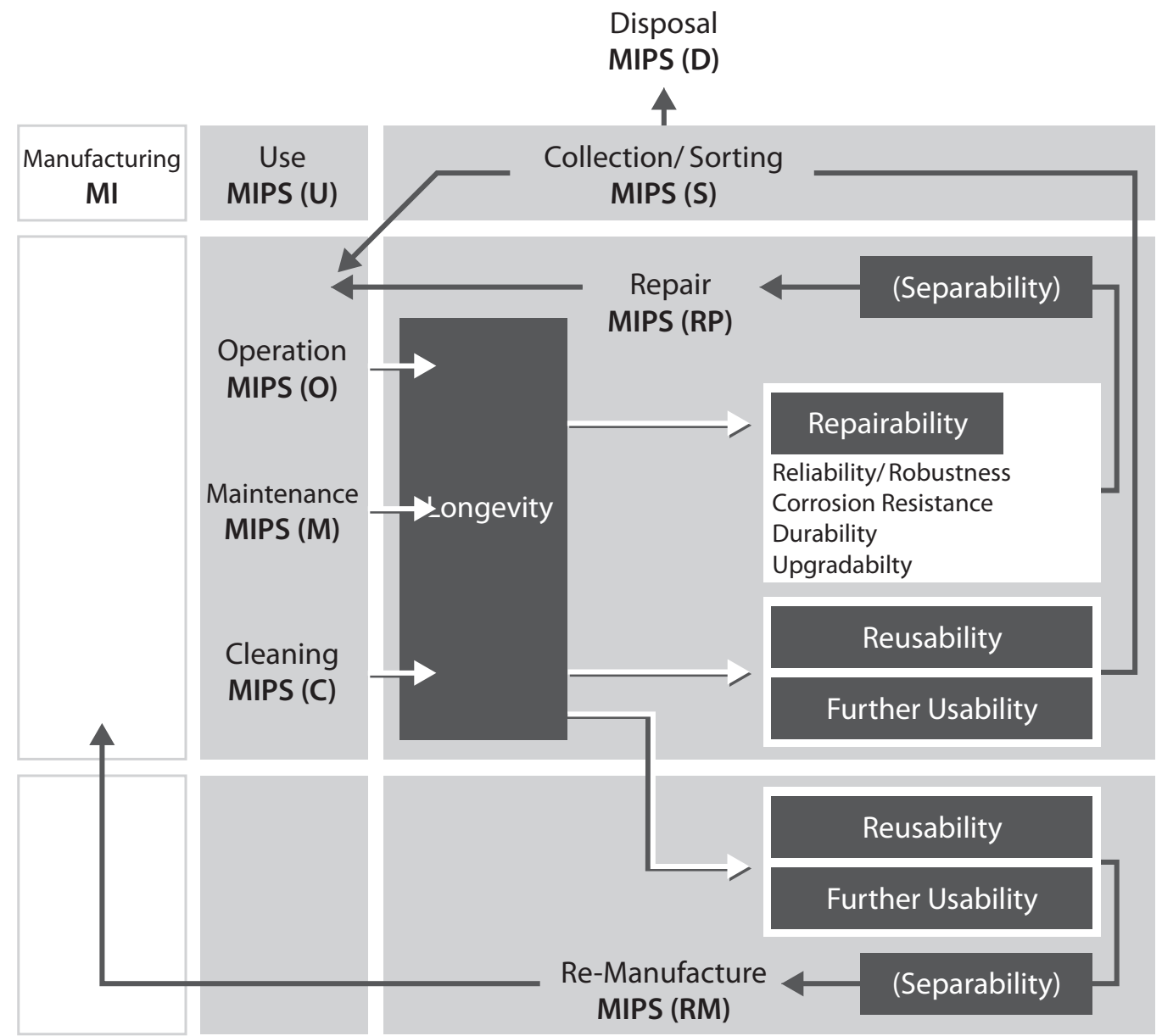

Source: Own depiction based on Schmidt-Bleek 1993, p. 73 
Figure 3: Phlox (example of housing sharing)

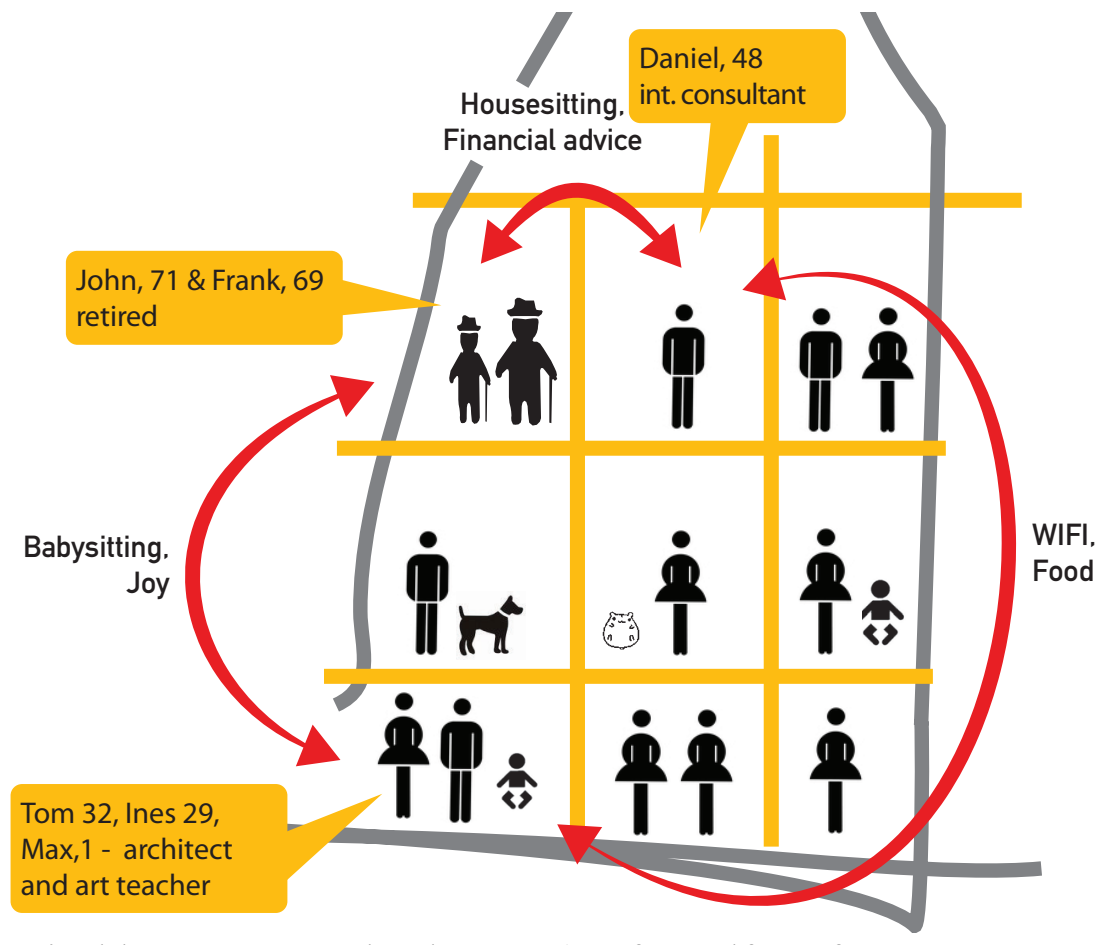

Source: 2ndSustainable Summer School 2010 (Prof. Wolf, Befort, Mertens, Matzky, Acar, Augsten, Hyngar )

Figure 4: FoodPrint (example of the composition of a menu)

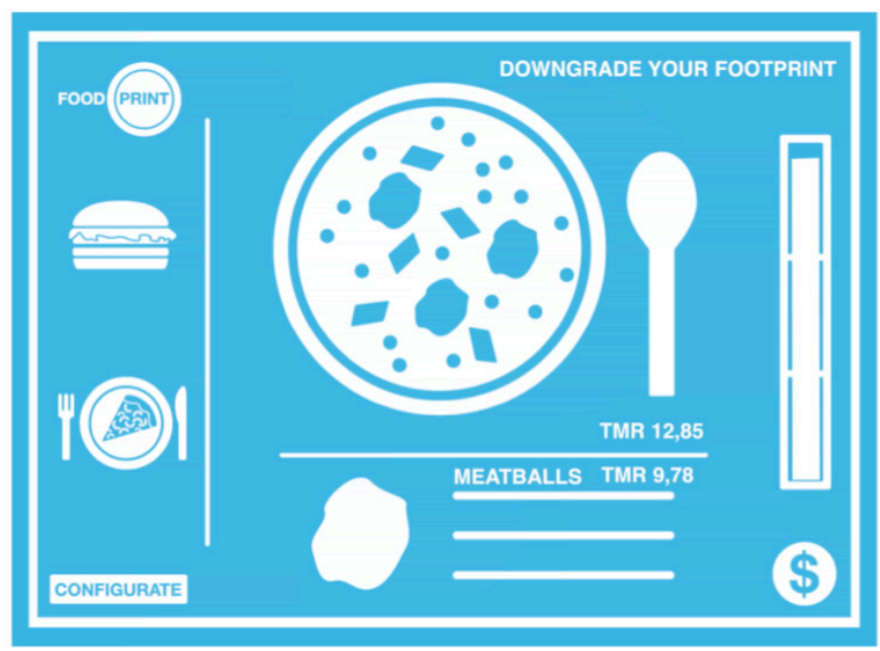

Source: 3rdSustainable Summer School 2011 (Prof. Gellersen, Schnellmann, Dobslaff, Erdal und Wiciok) 